\begin{tabular}{cc}
\hline Bentham open & The Open Mechanical Engineering \\
JoussMark & Content list available at: www.benthamopen.com/TOMEJ/ \\
DOI: $10.2174 / 1874155 \mathrm{X} 0161001000 \mathrm{C}$
\end{tabular}

\title{
A Design Method for a New Type of Cylindrical Roller Bearing Based on Edge Effect
}

\author{
Yao Qishui, Yang Wen, Li Chao and Yu Jianghong* \\ College of Mechanical Engineering, Hunan University of Technology, Zhuzhou 412007, China
}

Received: September 21, 2015

Revised: February 1, 2016

Accepted: February 11, 2016

\begin{abstract}
The elastic composite cylindrical roller bearing is a new type of bearing designed with polytetrafluoroethylene filling in a deep hole hollow roller. This design can improve the stress concentration and also performance of the bearing. A study was conducted to parameterize the deep hole structure to obtain its design variables, the angle a and radius c by studying the influence of the design on stress concentration in elastic composite cylindrical roller bearing edge; to determine the BP neural network sample data using orthogonal test and finite element methods; to establish mapping relationship between the design variables and the maximum stress by BP neural network learning algorithm and to obtain the objective function required for structural optimization of genetic algorithm. The study attempts to optimize, search and calculate the most fitting structural parameters of elastic composite cylindrical roller by genetic algorithm with NU318E bearing as the optimization object and obtain the values of optimal design variables as $\mathrm{a}=48.68^{\circ}$ and $\mathrm{c}=9.67 \mathrm{~mm}$. The work also includes minimization of the comprehensive value of the maximum contact stress and the maximum equivalent stress of the edge and elliptic zones of elastic composite cylindrical roller after optimizing and increasing the contact fatigue service and bearing capacity of the bearing. The optimization procedure and method presented in this paper can serve as a useful reference to the optimization of structure for other elastic composite cylindrical roller edges.
\end{abstract}

Keywords: BP neural network, contact stress, edge effect, elastic composite cylindrical roller, finite element, genetic algorithm, new type cylindrical roller bearing, stress concentration.

\section{INTRODUCTION}

Roller bearings are widely used in various types of rotary machine systems. The analysis of mechanical characteristics is the basis for research on service life of bearings. The straight bus cylindrical roller bearing has edge stress concentrated at two ends of roller, and it is called as "edge effect". It is the "edge effect" that causes the breakage of the roller bearing at two ends of the roller and both sides of the raceway. "The Edge effect" is an important reason for the fatigue destruction of roller bearing. The scholars in industry researched the "edge effect" problem of the roller bearings mainly for bus patching. G. Lundberg proposed the well-known Lundberg convexo formula [1] by theoretical analysis of bus in 1939. K. P. Singh and B. Paul proposed a simple discretization solution method and constituted a linear equation set and used them for calculating contact stress $[2,3]$ with convexo cylinder by unknown contact stress by citing influence coefficient method during the structural analysis. M. J. Hartnett proposed a new method, connecting the influence coefficient method and the relationship of half-space strength and deformation of J.Boussinesq, to solve the contact problem of the surface profile [4, 5]. J. W. Kannel and M. J. Hartnett [6] analyzed the dimension and distribution of the edge stress of the roller bearing. J. M. De Mul and J. J. Kalker [7] researched the distribution of the edge stress and the limited zone of the flexural stress. H. Reusner [8] employed the method of the semi-infinite model of rectangular unit, without assuming the contact as a semi-infinite body, which is dispersing the contact stress into several rectangular units instead of supposing that the contact half width is proportional to the maximum contact stress. Various types of the modified cylinder body were analyzed and log practice was considered as the best approach to

\footnotetext{
* Address correspondence to this author at the College of Mechanical Engineering, Hunan University of Technology, Zhuzhou, 412007, China; Tel: +86-731-22183978; E-mail: zzhngd@qq.com
} 
solve the edge effect. Ma Jiaju [9] established equations to solve stress from finite length line contact by applying the relationship between half-space strength and deformation of J. Boussinesq and solving the contacted problem between roller and raceway using Ahmadi numerical method. On the basis of Ma Jiaju research, Chen Xiaoyang [10] researched on the contact problem associated with the roller and inner and outer raceway of Lundberg logarithmic practice by using the influence coefficient and proposed the design method of convexity. Mao Yuexin [11] eliminated the heeling edge effect by adding convex metric and improved ability of the roller bearing to resist deflection. But the author did not design the convexity of roller. Wei Yangang $[12,13]$ calculated the contact stress between roller and raceway under the condition of heeling by using finite element method and proposed a practical concept of roller asymmetric body.

The method of bus patching is an established method to solve the problem of "edge effect". However, this method suffers from the disadvantages of high processing precision of patching curve and small load domain suitable for the patched cylindrical roller bearing. Wei Yangang et al. [14 - 17] developed a new bearing structure and on that basis proposed the deep hole hollow cylindrical roller bearing. The author's analysis by finite element method indicated that deep hole structure bearing could avoid and reduce the edge stress concentration of the cylindrical roller bearing. The author proved without detailed dimensional design and by experiment that the deep hole roller structure reduces or even prevents the contact "edge effect" of the roller.

The "edge effect" is caused by the contact between the bearing and the raceway. The techniques of numerical method and optimization algorithm were used in contact analysis. In 1980, the Swedish scholar, B. Fredriksson [18 20] used SAP5 around the convex, brought in the interface and reserved elements and analyzed the contact between the single rolling needle and the raceway. Besides, the cylindrical generatrix shape of the rolling needle was optimally designed by the virtual load method. Wan Changsen [21] pioneered a method of multiobjective roller bearing optimization and proposed the fatigue life, wear longevity, basic static load, friction moment and spin-to-roll ration as goals for optimization without specifying a detailed application example. He Shaowu et al. [22] proposed optimal design of the cylindrical roller bearing on the basis of genetic algorithm and annealing penalty function method and improved the global search ability and stability of the genetic algorithm. The CAD system of the roller bearing was thus solved. Zhao Guangyan et al. [23] proposed optimization procedure for the design of roller mill steep angle tapered roller bearing on the basis of coordinate exchange. Zhao Zhangrong et al. [24] conducted simple object optimization of tapered roller bearing on the basis of improved self-adaption genetic algorithm. Yang Xianqi et al. [25] conducted multiple target optimization of high speed angular contact by combining the quasi static design analysis method of ball bearing and "the ring raceway control hypothesis". Wang Dongfeng et al. [26] carried out multiple target optimization of double row angular contact ball bearing using the efficiency coefficient method.

The advances in computer applications led to wide use of finite element methods for the analysis of roller bearing. By using finite element analysis (FEA), Zhao [27] established 2D finite element model and applied it in calculating the load distribution inside the bearing subjected to static load. N. Demirhan et al. [28] established 2D finite element model of roller bearing that systematically calculated stress-strain under static load and validated it by actual tests. L. Zamponi et al. [29] established a mixed model of roller bearing and calculated the contact pressure and contact angle of roller bearing raceway with surface defect. Lin Tengjiao et al. [30] established a 3D finite element model ball bearing by using LS-DYNA and calculated on the basis of explicit dynamics method, the dimensions of inner and outer ring and holder of this model. They considered the model as a rigid body, and that roller used linear elastic materials, and found that the results of finite element and those from Hertz theory agreed well. Xu Hongyi et al. [31] established multi-body dynamics contact finite element model of roller bearing in the environment of ANSYS LS-DYNA and calculated the state of stress in low-speed bearing models of materials with different deformation constitutive relationships. In relation to non-specific roller bearing body research, Zupan et al. [32] calculated the elastic matrix of the structure by applying the finite element method to mechanical structure and determined the deformation of the over-all structure. The elastic composite cylindrical roller bearing is a new type of roller bearing in which polytetrafluoroethene (PTFE) materials are embedded in hollow deep hole roller in order to form an elastic composite cylindrical roller [33 - 35]. This approach is adopted since the rolling element of the elastic composite cylindrical roller bearing is more easily deformed than the solid cylindrical roller. Under the same load, the half-width of the contact between the roller element and the raceway increases while the contact stress diminishes. It is evident that when compared to the solid cylindrical roller, the force conditions of the elastic composite cylindrical roller bearing have improved. Owing to the reduction in flexural stress of the inner bore the ability to resist damage from anti-fatigue damage is enhanced and life of the composite cylindrical roller bearing is extended. In addition, the new type of roller bearing has obvious vibration-suppressing effect, because the embedded PTFE is very effective in absorbing shocks. Experimental evidence shows that the shock noise reduction 
effect of the elastic composite cylindrical roller bearing is better than the solid cylindrical and the hollow cylindrical rollers. As a result, the dynamic performance of the roller bearing and the entire mechanical system improved significantly. Because the proportion of the embedded PTFE $\left(2.2-2.3 \mathrm{~g} / \mathrm{cm}^{3}\right)$ is much less than that of the bearing steel $\left(7.80-7.58 \mathrm{~g} / \mathrm{cm}^{3}\right)$, the elastic composite cylindrical roller bearing has lighter weight and higher operating speed limit than the solid cylindrical roller bearing. The details of materials dimensions of proposed bearing are presented in (Fig. 1). Obviously the bearing possesses absorption and noise reduction effect and strong anti-fatigue destruction ability [36] because of the new structural form and excellent physicochemical characteristics PTFE.

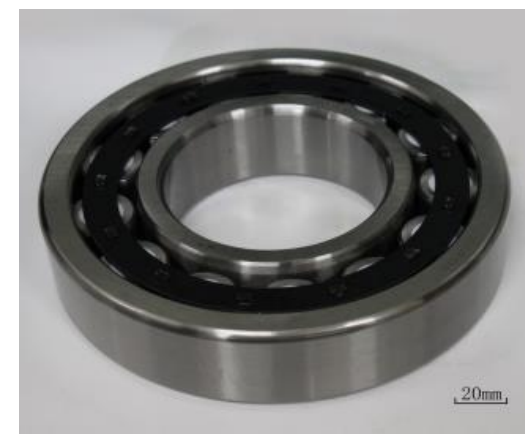

(a). Whole graph

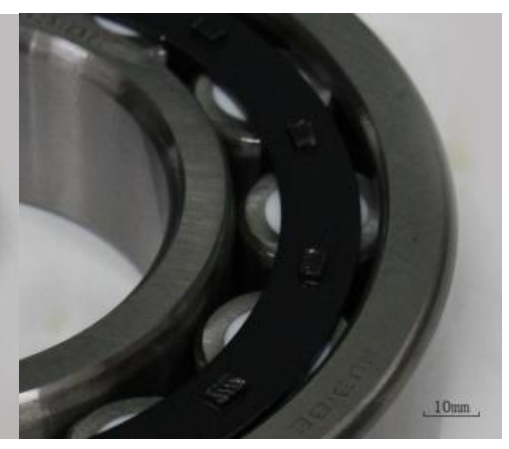

(b). Partial enlargement graph

Fig. (1). Real graph of elastic composite cylindrical roller bearing.

Achievements of the research group show that the edge structure of the elastic composite cylindrical roller bearing directly affects the edge stress distribution. Reasonable edge structure can reduce or even prevent the "edge effect".

This paper proposes an optimization method which combines the techniques of BP neural network and genetic algorithm and numerical analysis. The method is easy to use and applicable to the contact analysis of a non-linear structure for which mathematical model cannot be established. The numerical analysis was conducted under FEM and the sample for BP neural network was setup. The dimensions of an elastic composite cylindrical roller were optimized by BP neural network and genetic algorithm to improve the "edge effect" of elastic composite cylindrical roller bearing.

\section{ANALYSIS ON LINEAR CONTACT STRESS OF ELASTIC COMPOSITE CYLINDRICAL ROLLER}

The load distribution along the bus would be even only when the contact bodies are infinitely long or geometric lengths are absolutely equal according to the theory of elastic mechanics. The ideal linear contact between infinitely long cylinders does not exist in actual practice. In general, the roller is shorter than the width of collar roller path. Therefore, as shown in Fig. (2), materials are under tensile status by roller path recess out of roller end. The Press stress of the roller end will exceed the stress at contact center [37].

In Fig. (3) for the elastic composite cylindrical roller shown:

$$
\begin{aligned}
& L=\text { roller length } \\
& D=\text { roller diameter } \\
& d=\text { material filling diameter } \\
& \alpha=\text { deep hole angle of roller } \\
& c=\text { deep hole radius of roller } .
\end{aligned}
$$

The contact half-width of the roller and bearing roller path increase while the contact stress decreases for the same load as the elastic composite cylindrical roller made from embedded PTFE materials is easier to be deformed compared to the solid cylindrical roller. The contact rigidity at the two ends is less than that of the central portions of elastic composite cylinder roller because of the deep hole structure. The ends are easy to deform during the contact of the roller and the inner and outer rings and solving the roller edge stress concentration problems, will decrease contact stress of bearings and increase contact fatigue service effectively [15]. 


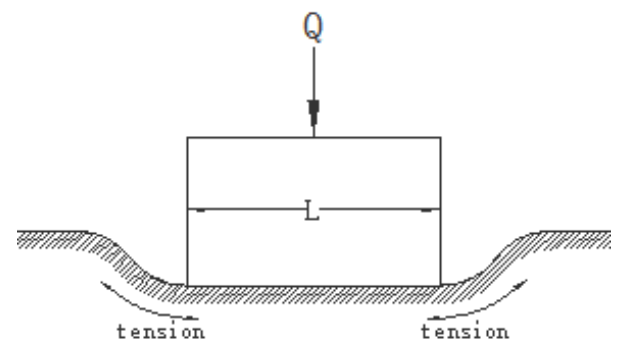

(a). Roller and infinite length surface contact

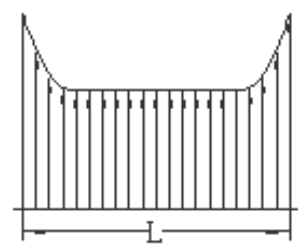

(b). Press stress distribution of roller and roller path

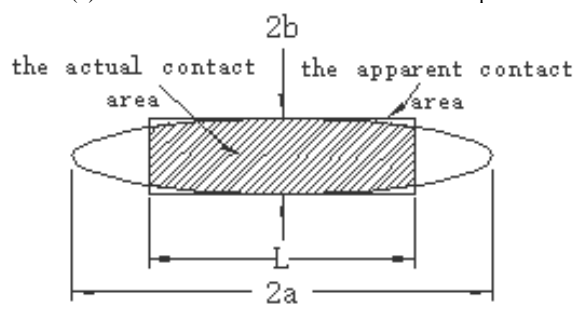

(c). Contact ellipse

Fig.(2). Linear contact

Fig. (2). Linear contact.

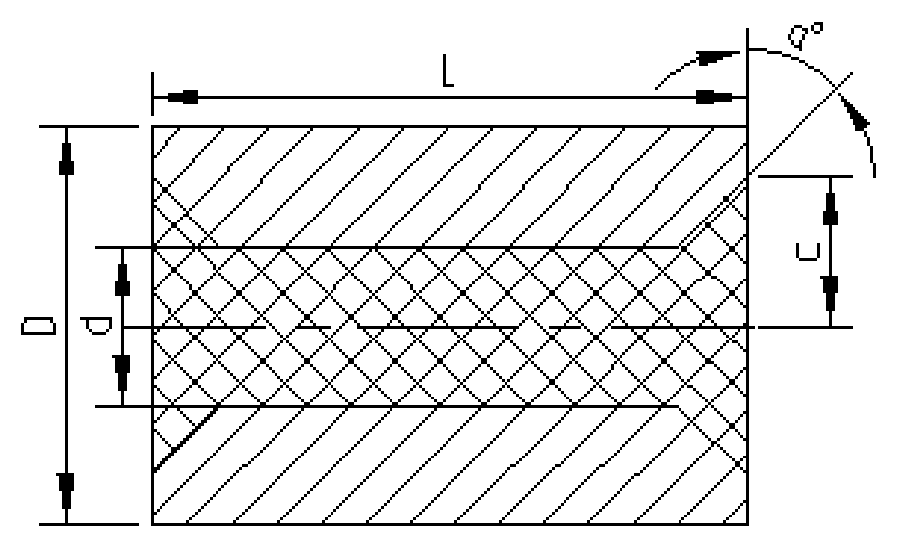

Fig. (3). Cross-sectional view of elastic composite cylindrical roller.

\section{ANALYSIS ON DEEP HOLE DESIGN VALUE OF ELASTIC COMPOSITE CYLINDRICAL ROLLER}

During fatigue materials crack easily in stress concentration zone. The "Edge effect" will decrease the fatigue of the bearing in service greatly. This is because the fatigue is in inverse proportion to 7 to 9 power of stress as shown in the published research [38].

The value analysis was carried out for the deep hole design of elastic composite cylindrical roller bearing to determine the influence of the design dimensions of the deep hole structure on stress concentration at elastic composite cylindrical roller bearing edge. 


\subsection{Determination of the Geometric Dimensions of Model and the Material Characteristics}

The outline dimensions of the elastic composite cylindrical roller bearing NU318E, as shown in Table $\mathbf{1}$ were selected, by referring to GB/T283-2007 and GB/T4661-2002. The roller dimensions depend on the deep hole angle, $a$ and deep hole radius, $c$. They were selected as variables for optimization. $\alpha$ ranged in $\left(0^{\circ}, 90^{\circ}\right)$; and $c$ in $(d / 2, D / 2)$. The selected values of $a$ were $30^{\circ}, 45^{\circ}, 60^{\circ}$ and $75^{\circ}$ and those of $c$ were $8.4 \mathrm{~mm}, 9.1 \mathrm{~mm}, 9.8 \mathrm{~mm}$ and $10.5 \mathrm{~mm}$. These enabled formation of 16 groups according to Orthogonal-Test-Method.

Table 1. The dimensional parameters of NU318E bearing.

\begin{tabular}{|c|c|c|}
\hline Inner diameter of bearing, $\mathrm{d} / \mathrm{mm}$ & 90 & Roller diameter, D/mm \\
\hline Outer diameter of bearing, $\mathrm{D}_{1} / \mathrm{mm}$ & 190 & Roller length, $\mathrm{L} / \mathrm{mm}$ \\
\hline Bearing width, B/mm & 43 & Roller quantity, Z/pcs \\
\hline
\end{tabular}

As shown in Fig. (4), 1/2 of roller, 1/4 of inner ring and 1/16 of outer ring were used as finite element analysis model to simplify the analysis on considerations of structural and load characteristics and symmetry of the roller bearing. The inner/outer rings and roller were GCr15 bearing steel, with elastic modulus of 207GPa and Poisson's ratio of 0.3. The elastic modulus and Poisson's ratio for PTFE embedded elastic composite cylindrical roller respectively were, $280 \mathrm{MPa}$ and 0.4 . The material attributes were defined, created and distributed as sectional attributes by the above parameters.

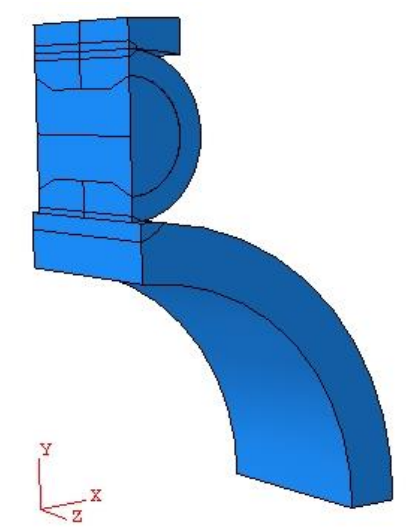

Fig. (4). The finite element analysis model of elastic composite cylindrical roller bearing.

The analysis was carried out by selecting $55 \%$ of roller compactness and by considering of the optimal capacity and fatigue service of the elastic composite cylindrical roller bearing. (Compactness $K=d / D$; where, $D$ is the roller diameter; $d$ is diameter of material filling).

\subsection{Definition Border and Load}

The ABAQUS provides several types of connection restriction methods for different material quality or types of unit parts [39]. It has to adopt the symmetry constraint for the symmetry of the model. The bottom cross section of inner ring was restrained in U1, U2 and U3 directions. The left cross section of roller and inner and outer rings was restrained. U1, UR2 and, UR3 were made equal to zero. The U3 restraint for longitudinal center line of left cross section was carried out Constraints are shown in Table 2.

Table 2. Constraint.

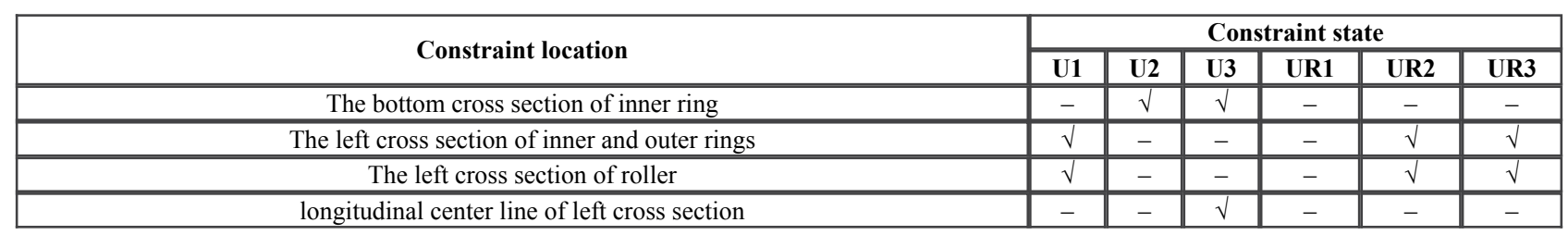

Under the effect of static load the sum of the maximum roller bearing capacity at $0^{\circ}$ orientation and the load on upper lateral surface of the outer ring after the converting loading area was $2.5 \times 10^{7} \mathrm{~Pa}$ according to the load distribution in elastic composite cylindrical roller bearing. 


\subsection{Contact Establishment and Mesh Division}

There are two types of materials between the roller and inner and outer rings of the model. These materials in elastic composite cylindrical roller are designed to play a role in load bearing and transfer. The contact pairs on the roller contact surface are set from facing towards the inner and outer rings and the roller by using the contact surface of the inner and outer rings as the main surface and the outer wall of the filling materials as the auxiliary surface. The contact pairs are established for filling materials and hollow roller by using the inner wall of roller as the main surface.

Whether the simulation calculations can be completed smoothly, quickly and accurately depends directly on how well the mesh division is done. The secondary non-linear 3D space unit C3D15 was used for symmetry model of the entire shaft by considering the geometric shape, load conditions and the material combination, etc. of the research target. A close relationship exists between the precision of finite element analysis and efficiency, density and geometric shape of unit. Super-fine mesh may extremely prolong the calculation period while the highly-loose mesh may make it difficult to describe the space variation of the field variables. Therefore, properly refined gridding can increase the calculation precision. The other integrating parts can be divided approximately to reduce the calculation time without influencing the precision. The Gridding division is shown in Fig. (5). The gridding division of 29243 nodes and 15679 units shown in Fig. (6) is considered as reasonable.

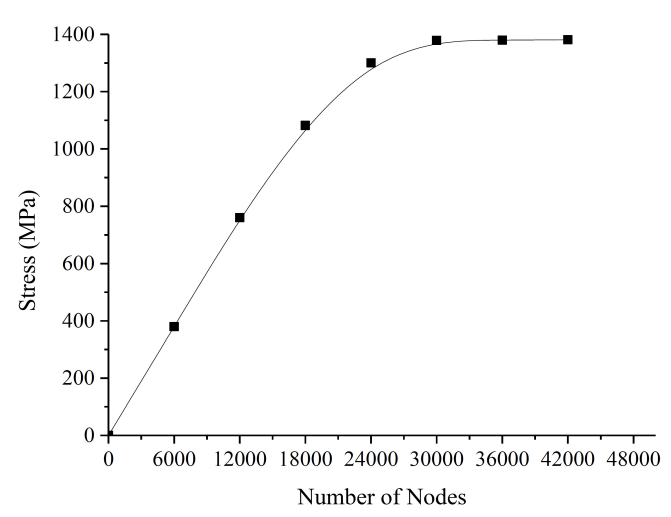

Fig. (5). The relationship between the model node number and stress value.

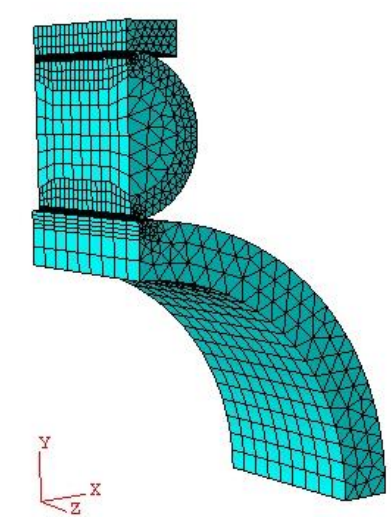

Fig. (6). Elastic composite cylindrical roller bearings mesh finite element analysis model.

\subsection{Results and Analysis}

The maximum equivalent stress and the contact stress existing in roller contact zone are obtained by finite element analysis and calculation under the loading of elastic composite cylindrical roller bearing. The maximum equivalent stress and contact stress in the roller edge contact zone and elliptical contact zone are isolated and analyzed. Figs. (7), (8) are the equivalent stress diagram and contact stress diagram respectively of the contact zone of the elastic composite cylindrical roller. In this figure the transverse coordinate $c$ refers to deep hole radius. The deep hole angle is marked in the legend. "BY" refers to the edge contact zone. "TY" refers to the elliptical contact zone. 


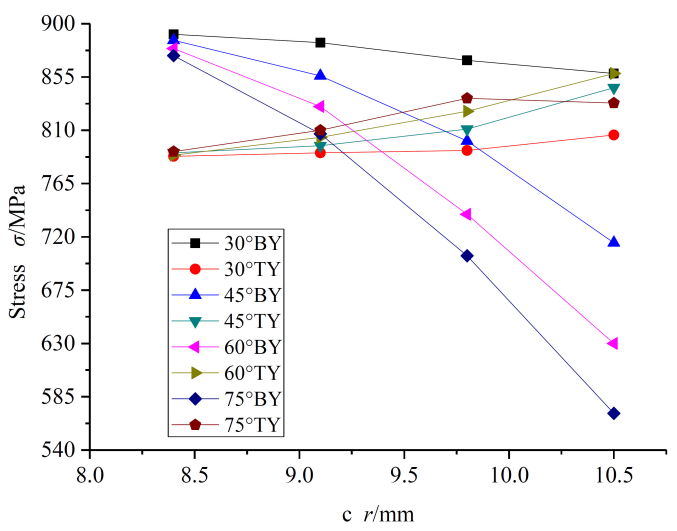

Fig. (7). Maximum equivalent contact region of elastic composite cylindrical roller.

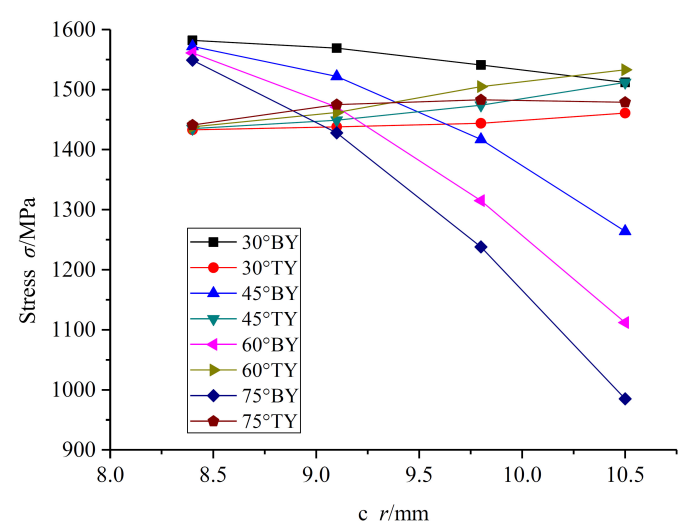

Fig. (8). Maximum contact stress region of elastic composite cylindrical roller contact.

From the analysis of Figs. (7), (8), it can be seen that both the maximum equivalent stress and the maximum contact stress vary with deep hole angle and radius in the edge contact zone of elastic composite cylindrical roller. The maximum equivalent stress and the maximum contact stress decrease with the deep hole radius increasing when the deep hole angle is kept constant. The stress reduction amplitude increases with increasing deep hole angle.

The maximum equivalent stress and the maximum contact stress increase with increasing deep hole radius in elliptical contact zone of elastic composite cylindrical roller, when deep hole angle varies between $30^{\circ}$ to $60^{\circ}$. This increase in maximum equivalent stress and the maximum contact is monotonously not monotonous for deep hole angle of $75^{\circ}$. The maximum equivalent stress and the maximum contact stress decrease as deep hole radius increase from $9.8 \mathrm{~mm}$ to $10.5 \mathrm{~mm}$.

The results presented in Figs. (6), (7) indicate that the maximum contact stress and equivalent stress in edge contact zones of the elastic composite cylindrical roller increase regardless of the variation of the deep hole angle when deep hole radius is in the range of $8.4-9.1 \mathrm{~mm}$. Stress concentration exists from view of values. The contact stress and equivalent stress in the edge contact zones of the elastic composite cylindrical roller decrease with increasing deep hole radius. The edge stress does not exist basically as the contact stress and equivalent stress in the elliptical zone increase. In addition, it is essential to consider the optimization of deep hole structural dimensions of elastic composite cylindrical roller under non-equivalent stress values in the edge zone and elliptical zones. The optimization and analysis carried out by relying on BP neural network and genetic algorithm are as follows.

\section{OPTIMIZATION OF DEEP HOLE STRUCTURE OF ELASTIC COMPOSITE CYLINDRICAL ROLLER}

The results obtained from finite element analysis of elastic composite cylindrical roller bearing show that large stress may exist in roller edge and elliptical zones. It is necessary to optimize the structural parameters to increase the fatigue service life of the elastic composite cylindrical roller bearing to minimize the stress in edge and elliptical zones of the elastic composite cylindrical roller under the conditions that structural rigidity requirements are met. It is crucial to establish a reasonable mathematical optimization model for determining these stress values in edge and elliptical zones. 
The objective function for structural optimization can be formulated according to the special structural form of the elastic composite cylindrical roller and defined by following Eqs. (1) and (2):

$$
\begin{aligned}
& p_{i}=f_{1}(a, c) \\
& p_{j}=f_{2}(a, c)
\end{aligned}
$$

The multiple-objective problems can be converted to a single-objective optimization problem by utilizing weighted sum method. The single objective function, $f$ can be written as,

$$
f=m p_{i}+n p_{j}
$$

In Eq. (3) $P$ is the maximum stress in elastic composite cylindrical roller edge; $P$ is the maximum stress in elastic composite cylindrical roller ellipse; $m$ and $n$ are weighted coefficients. Thus the structural optimization problem is converted to optimize the parameters $\alpha$ and $c$ by obtaining the minimum value of objective function $f$.

It is difficult to propose a mathematical model from theory for a special structure like elastic composite cylindrical roller. The Neural network model can provide a mapping relationship for non-linear function to obtain approximate objective function required for generating solutions to structural optimization problem by genetic algorithm. The effective integration of neural network and genetic algorithm is crucial to optimize the structural parameters.

\subsection{BP Neural Network}

BP neural network algorithm is widely employed to solve the optimization problems by training and mathematical model without knowing target. It is often used in MATLAB for the construction of objective function [40 - 42]. The mapping functions have to be obtained for special structure of elastic composite cylindrical roller by neural network algorithm. This paper shows the calculations for instructing and training the samples by 3-layer BP neural network. The Input layer has 2 variables, namely, deep hole angle $\alpha$ and deep hole radius $c$; The quantity of implicit strata is selected as 6 so that the output layers are $P, P$ and $f$. For value analysis data on 16 samples were selected as BP neural network training sample. The results show excellent agreement between the network output and sample objectives. The trained mapping functions retained tool kit in the neural network for recalling during optimization by genetic algorithm.

\subsection{Genetic Algorithm}

Genetic algorithm is a highly efficient parameter optimization method for global optimization. It solves the nonlinear contact problems excellently [43 - 45].

\subsubsection{Production of Initial Population}

In general, genetic algorithm uses floating-coding method by aiming the continuous variable functions. The floating-coding has excellent gradually changing ability to eliminate the "Hamming cliff" and facilitate the treatment of restraint conditions at the same time. The binary system coding has no such characteristics.

\subsubsection{Fitness Function}

Individual fitness is based both on individual fitness assessment standard and population evolution. The penalty technique is the most common method used in obtaining solution to constrained optimization problems by genetic algorithm. It is essential is to convert the restraint problems to non-restraint problems by penalty non-feasible solutions. The feasible and non-feasible solutions coexist [46].

Fitness assessment function is as follows:

$$
F(x)=f(x)+r P(x)
$$

In this Eq. (4), $F(X)$ is fitness function; $P(X)$ is penalty function; $f(X)$ is neural network mapping function.

\subsubsection{Design Genetic Operator}

The population evolution was carried out by utilizing the genetic algorithm and by generating a new generation of population on the basis of previous generation of individuals.

Operators were selected on the basis of survival of the fittest for individuals in the population and fitness evaluation for calculating genetics of next generation of population. The characteristics of the fitness proportion selection method 
are that the selection probability of various individuals and fitness is in direct proportion. The optimal individual storage method is to match the crossing of individuals of the maximum fitness in population and directly copy to the next generation. The optimal solutions of a certain generation during evolution will not be destroyed by crossing or mutation operation. This objective of this paper is to combine the proportional selection and the optimal individual storage to increase the efficiency and convergence of calculations.

Crossing calculation is the main method to generate new individuals by genetic algorithm. It plays a key role in the algorithm. The coordination of crossing operator design and encoding design is a basic requirement of the crossing calculation. The arithmetic crossing method was adopted for floating-coding chromosome to generate two new individuals by linear combination of two old ones.

The mutation calculation refers to replacing some genes in individual coding by other multiple alleles of small mutation probability randomly to form two new individuals. The floating-coding was used to increase the local searching ability and convergence speed of genetic algorithm. The floating-coding individuals generate new individuals during mutation. The floating-coding mainly combines the self-adaptation mutation and non-uniform mutation.

\subsection{Structural Optimization}

The procedure for setting-up the main control parameters of genetic algorithm: Population size [47], $\mathrm{M}=10$; Crossover probability, $P=0.6$; Initial mutation probability, $P=0.06$; Terminate algebra, T=250; Crossover parameter, $a=0.2$; Initial value of parameter $\mathrm{b}$ of adjustment mutation step length is 1.0 ; Weighted coefficients $m$ and $n$ are 0.91 and 1.05 respectively.

The optimal calculation results are shown in Table 3 after operation of genetic algorithm 250 power. Optimized values of design variable are as follows: $\alpha=48.68^{\circ} ; c=9.67 \mathrm{~mm}$; the maximum stress in edge zone and elliptic zone of elastic composite cylindrical roller under optimized value of design variable are as follows: $P=773 \mathrm{MPa} ; P=738 \mathrm{MPa}$; they decrease by $9.7 \%$ and $7.4 \%$ respectively before optimization. Optimization variables of genetic algorithm are the optimal solutions by comprehensive contrast of weighted values.

Table 3. Comparison of the variables before and after optimization.

\begin{tabular}{|c|c|c|c|c|}
\hline Parameter & $\boldsymbol{a} /{ }^{\circ}$ & $\boldsymbol{c} / \mathbf{m m}$ & $\boldsymbol{P}_{i} / \mathbf{M P a}$ & $\boldsymbol{P}_{j} / \mathbf{M P a}$ \\
\hline Before optimization & 45 & 9.1 & 856 & 797 \\
\hline After optimization & 48.68 & 9.67 & 773 & 738 \\
\hline
\end{tabular}

\section{CONCLUSION}

1. Two design variables namely, the deep hole angle, a and deep hole angle, $\mathrm{c}$ were studied. The results from finite element analysis showed that contact stress and equivalent stress in edge zone of the elastic composite cylindrical roller decrease as $a$ or $c$ increases; the contact stress and equivalent stress in elliptical zone also increase; both of them decrease when the deep hole angle reaches $75^{\circ}$.

2. For the NU318E type bearing which was taken as the object of optimization, the optimal structural dimensions were determined as: $\alpha=48.68^{\circ}$ and $c=9.67 \mathrm{~mm}$.

3. The optimization process and method demonstrated in this paper should provide a useful reference for similar applications to other types of elastic composite cylindrical roller edge structure.

\section{CONFLICT OF INTEREST}

The authors confirm that this article content has no conflict of interest.

\section{ACKNOWLEDGEMENTS}

This project is supported by National Natural Science Foundation of China (Grant No. 51175168), Hunan Provincial Science and Technology key Project of China (Grant No.2014GK4014), the national finacial for innovation team of China (Grant No.0420036017).

\section{REFERENCES}

[1] G. lundberg, "Elastische beruhrung zweier halbraeum", Forschung Auf Dem Gebiet Des Ingenieurwesens A, vol. 10, pp. 201-211, 1939. 
[2] K.P. Singh, and B. Paul, "Numerical solution of Non-Hertzian elastic contact problems, Trans ASME", Appl. Mech., vol. 41, pp. 484-490, 1974. [http://dx.doi.org/10.1115/1.3423314]

[3] K.P. Singh, and B. Paul, "Stress concentration in crowned rollers", J. Eng. Ind., vol. 97, pp. 990-994, 1975. [http://dx.doi.org/10.1115/1.3423314]

[4] M.J. Hartnett, "The analysis of contact stresses in roller element bearings", J. Lubr. Technol., vol. 101, pp. 105-109, 1979. [http://dx.doi.org/10.1115/1.3453270]

[5] Y.P. Chiu, and M.J. Hartnett, "A numerical solution for the contact problem involving bodies with cylindrical surface considering cylinder effect. Trans. ASME", J. Tribol., vol. 109, pp. 479-485, 1987. [http://dx.doi.org/10.1115/1.3261478]

[6] J.W. Kannel, and M.J. Hartnett, "Theoretical and experimental evaluation of edge stresses under severe edge loads", ASLE Trans., vol. 26, pp. 25-30, 1983. [http://dx.doi.org/10.1080/05698198308981473]

[7] J.M. de Mul, J.J. Kalker, and B. Fredriksson, "The contact between arbitrarily curved bodies of finite dimensions", J. Tribol., vol. 108, pp. $140-148,1986$.

[http://dx.doi.org/10.1115/1.3261134]

[8] H. Reusner, "Logarithmic roller profile-the key to superior performance of cylindrical and taper roller bearings", Ball Bearing J., vol. 230, pp. $2-10,1987$.

[9] J. Ma, Elastic Contact Force and Deformation Calculation of Roller Bearing. Luoyang Bearing Research Institute: Luoyang, 1977.

[10] X. Chem, Research on Optimal Design and CAD Needle Roller Bearing. Zhejiang University: Hangzhou, 1989, pp. 3-15.

[11] Y. Mao, X. Shen, and X. Chen, "Study on contact stress distribution of roller bearings and roller profile design under misaligned loads", Zhongguo Jixie Gongcheng., vol. 20, pp. 1918-1922, 2009.

[12] Y. Wei, and Q. Jiang, "Unsymmetric shape modification of cylindrical roller bearings", J. Mach. Des., vol. 20, pp. 17-19, 2003.

[13] Y. Wei, Z. Ge, and Q. Jiang, "Finite element analysis of cylindrical rollers under nonuniform load used in shaft boxes beering of high-speed vehicles and unsymmetric modification of the rollers", Lubr. Eng., vol. 2, pp. 9-11, April 2002. [http://dx.doi.org/10.1115/1.3423314]

[14] Y. Wei, "Research on the performances of a novel roller bearing-deep cavity hollow cylindrical roller bearing", Chin. J. Mech. Eng. (Chin. Ed.)., vol. 41, pp. 107-111, 2005.

[15] Y. Wei, Q. Jiang, and Q. Yi, "A novel roller bearing-deep cavity roller bearing and its finite element analysis", Zhongguo Jixie Gongcheng., vol. 12, pp. 2078-2080, 2002.

[16] Y. Liu, and Y. Wei, "Design of experiment method of deep-hollow roller contact effect", J. Dalian Jiaotong Univ., vol. 28 , pp. $20-23$, 2007.

[17] Y. Wei, and M. Li, "Experiment study of roller contact edge effect", J. Dalian Railw. Inst., vol. 27, pp. 25-28, 2006.

[18] M.R. Hoeprich, "Rolling element bearing contact geometry analysis", Tribol. Trans., vol. 38, pp. 879-882, 1995. [http://dx.doi.org/10.1080/10402009508983484]

[19] T.A. Harris, Rolling Bearing Analysis., 5th ed. John Wiley \& Sons: New York, 2006.

[20] M.R. Hoeprich, "Process For Deriving The Contact Geometry For Raceways And Rollers Of A Roller Bearing", U.S. Patent 4,877,340, October 31, 1989.

[21] C. Wan, The Analysis Method of the Roller Bearing. China Machine Press: Beijing, 1985.

[22] S. He, Y. Wu, and G. Zhou, "Research on the methods of optimal design of taper roller bearing based on improved genetic algorithm", Modu. Mach. Tech., vol. 27, pp. 1-3, 2006.

[23] G. Zhao, Optimal Design and Calculation Analysis of Large Cone Angle Thrust Tapered Roller Bearing For Roller Mills. Hefei University of Technology: Heifei, 2004, pp. 6-10.

[24] Z. Zhao, I. Sui, and Y. Huang, "Optimal design of taper roller bearing based on improved adaptive genetic algorithm", Mach. Tool \& Hyd., vol. 36, pp. 21-23, 2008.

[25] X. Yang, S. Jiang, and J. Chen, "Optimal design of high-speed angular contact ball bearing", Bearing, vol. 43, pp. 1-5, 2000.

[26] D. Wang, J. Ye, and B. Yang, "Optimal design of the double row angular contact ball bearing", Bearing, vol. 51, pp. 8-10, 2008.

[27] H. Zhao, "Analysis of load distribution within solid and hollow roller bearings", J. Tribol., vol. 120, pp. 134-139, 1988.

[28] N. Demirhan, and B. Kanber, "Stress and displacement distributions on cylindrical roller bearing rings using FEM", Mech. Based Des. Struc., vol. 36, pp. 86-102, 2008. [http://dx.doi.org/10.1080/15397730701842537]

[29] L. Zamponi, E. Mermoz, and J.M. Linares, "Impact of geometrical defects on bearing assemblies with integrated raceways in aeronautical gearbox", Mechanism Mach. Theory, vol. 44, pp. 1108-1120, 2009. [http://dx.doi.org/10.1016/j.mechmachtheory.2008.10.005] 
[30] T. Lin, Q. Rong, and R. Li, "Deep groove ball bearing operation process dynamic characteristics of the finite element analysis", J. Vib. Shock., vol. 28 , pp. $118-122,2009$.

[31] H. Xu, and C. Zhang, "Finite element analysis of roller bearing based on the plastic material models", Chin. J. Mech. Eng. (Chin. Ed.)., vol. 46, pp. 29-35, 2010.

[32] S. Zupan, and I. Prebil, "Carrying angle and carrying capacity of large single row ball bearing as a function of geometry parameters of the roller contact and the supporting structure stiffness", Mechanism Mach. Theory., vol. 36, pp. 1087-1103, 2001. [http://dx.doi.org/10.1016/S0094-114X(01)00044-1]

[33] Q. Yao, W. Yang, J. Yu, and R. Zhang, "Research on structure design of elastic composite cylindrical roller bearing", Zhongguo Jixie Gongcheng., vol. 23, pp. 2899-2902, 2012.

[34] Q. Yao, "Improve the Cylindrical Roller Bearing Fatigue Method and Elastic Composite Cylindrical Roller Bearing", China Patent 201110061171.1 , July 7, 2011.

[35] Q. Yao, "A kind of elastic composite cylindrical roller bearing", China Patent 201120066406.1, November 23, 2011.

[36] W. Yang, Q. Yao, J. Yu, R. Zhang, and Q. Yao, "Research of carrying capacity of elastic composite cylindrical roller bearing", J. Mech. Trans., vol. 37, pp. 6-9, 2013.

[37] T.A. Harris, Roller Bearing Analysis: Basic Concepts of Bearing Technology, vol. 1. China Machine Press: Beijing, 2009.

[38] E.V. Zaretsky, "A. Palmgren revisted-a basis for bearing life prediction", Lubr. Eng., vol. 54, pp. 18-25, 1998.

[39] Y. Shi, and Y. Zhou, Example Explanation of Finite Element Analysis. China Machine Press: Beijing, 2006.

[40] Q. Wang, Y. Zhang, and Y. Zhu, "Neural network compact ensemble and its applications", Chin. J. Mech. Eng. (Engl. Ed.)., vol. 23, pp. 209-216, 2010.

[41] P. Li, S. Huang, and W. Zhang, "Optimum design method of structure based on neural network and genetic algorithm", J. Guilin Univ. Technol., vol. 27, pp. 128-132, 2010.

[42] C. Wang, R. Zhu, and W. Wang, "Optimization of die casting processing parameters based on BP neural network and GA algorithm", J. Plast. Eng., vol. 18, pp. 105-110, 2011.

[43] G. Zhang, and K. Gu, "Optimization of nonlinear structure based on genetic algorithm and parametrized model", Chin. J. Comput. Mech., vol. 20, pp. 764-768, 2003.

[44] A. Borboni, R. Bussola, and R. Faglia, "Movement optimization of a redundant serial robot for high-quality pipe cutting", J. Mech. Des., vol. 130, pp. 082301-1, 082301-082306, 2008. [http://dx.doi.org/10.1115/1.2918907]

[45] L. Chen, Genetic Algorithm Optimization of Mechanical Design. China Machine Press: Beijing, 2005.

[46] Y. Xing, Y. Hu, and J. Sun, "Finite element analysis on crowning of roller with logarithmic profile", J. Harbin Bearing., vol. 31, pp. 1-5, 2010 .

[47] Y. Liu, W. Shen, and Y. Wei, "Affect of roller profile on stress in cylindrical roller bearings", Bearing., vol. 50, pp. 1-3, 2007.

C Qishui; et al.; Licensee Bentham Open.

This is an open access article licensed under the terms of the Creative Commons Attribution-Non-Commercial 4.0 International Public License (CC BY-NC 4.0) (https://creativecommons.org/licenses/by-nc/4.0/legalcode), which permits unrestricted, non-commercial use, distribution and reproduction in any medium, provided the work is properly cited. 